\title{
A generalised damage model for constant amplitude fatigue loading of adhesively bonded joints
}

H. Khoramishad ${ }^{\mathrm{a}}$, A.D. Crocombe $\mathrm{C}^{\mathrm{a}, 1}$, K.B. Katnam ${ }^{\mathrm{a}}$ and I.A. Ashcroft ${ }^{\mathrm{b}}$

${ }^{a}$ Mechanical, Medical and Aerospace Engineering, Faculty of Engineering and Physical Sciences (J5), University of Surrey, Guildford, Surrey GU2 7XH, UK.

${ }^{\mathrm{b}}$ Wolfson School of Mechanical and Manufacturing Engineering, Loughborough University, Leicestershire LE11 3TU, UK

\begin{abstract}
The fatigue resistance of adhesively bonded joints is an important aspect of reliable structural design in many sectors. In this paper, the effect of load ratio on the fatigue behaviour of adhesively bonded joints was investigated using both experimental and numerical approaches. Single lap joints were tested under cyclic loading at different load ratios and load levels to characterise their response. A numerical model that accounts for the load ratio effect in constant amplitude fatigue loading was developed to predict the response of these bonded joints. The progressive damage of the adhesive material was modelled using a cohesive zone approach with a bi-linear traction-separation response. Damage initiation and propagation phases were monitored using the backface-strain and in-situ video-microscopy techniques. The load ratio effect on the fatigue behaviour of adhesively bonded joints was successfully predicted using a strain-based fatigue damage model. The numerical results were found to be in good agreement with the experimentally observed fatigue damage evolution and failure life.
\end{abstract}

\footnotetext{
${ }^{1}$ Corresponding author. Tel.: +44 (0)1483 689194; fax: +44 (0)1483306039.

E-mail address: a.crocombe@surrey.ac.uk (A.D.Crocombe).
} 


\section{Introduction}

Adhesively bonded structural joints have been widely employed in various industries because of their advantages over the classical mechanical fastening methods. Such advantages include better fatigue resistance, eliminating fretting fatigue, reduction in structural weight, better sealing and vibration-damping properties and reductions in manufacturing costs. Although adhesively bonded structural joints benefit from relatively higher fatigue strength in comparison with other mechanical fastening techniques, fatigue damage is still one of the major causes of failure. Moreover, fatigue testing is often costly and time consuming whilst predictive numerical models can reduce time and cost, and effectively help engineers to minimise the experimental effort required to attain a reliable structural design.

Constant amplitude fatigue loading is characterised by three load parameters: (a) maximum fatigue load, (b) load ratio ( $R$, the ratio of minimum to maximum fatigue load), and (c) frequency. The effect of these fatigue load parameters depends on the type of adhesive system and the joint configuration being used. Although extensive work has been undertaken in investigating the effect of fatigue loading characteristics on the fatigue behaviour of metals, relatively few studies have been dedicated to the fatigue of polymeric adhesive systems. The effect of load ratio has been found to be significant in the fatigue response of polymeric materials [1-3]. It was observed that increasing the load ratio for a constant maximum fatigue load increased the fatigue life [2-4] and, conversely, for a constant load range, an increased load ratio has a deleterious influence on the fatigue response [1]. However, the effect of 
frequency on adhesively bonded joints was found to be less important $[1,4]$. Therefore, in many cases, the maximum fatigue load and the load ratio determine the fatigue response of adhesively bonded joints.

Underhill and DuQuesnay [4] studied the influence of surface pre-treatment and load ratio on the fatigue behaviour of adhesively bonded joints. They showed that in poorly bonded joints, the maximum fatigue load governs the fatigue behaviour whilst the load ratio has little influence. This was because as soon as the maximum load is applied the weak bond becomes totally damaged, leading to joint failure. Conversely, with good bonding, because of the strong connection between the substrate and the adhesive, total failure did not occur as soon as the maximum load was applied and other fatigue loading characteristics, such as load ratio affected the fatigue response.

The fatigue damage response of adhesively bonded joints has been modelled by several researchers [5-7] using finite element modelling. In these models, the adhesive material properties were degraded based on a fatigue damage variable to simulate the deleterious effect of fatigue. Graner Solana et al [6] and Shenoy et al [5] reduced the elastic and plastic properties of the adhesive bond line based on a damage variable. Khoramishad et al [7] utilised a cohesive zone model to simulate the progressive damage in the adhesive bond line and degraded the cohesive zone properties to model fatigue damage. Then, Katnam et al [8] extended this fatigue model in a preliminary attempt to incorporate the load ratio effect. However, they did not take the sensitivity of the adhesive system to the variation of the load ratio into consideration and hence their model could only be used for a limited range of adhesive systems. 
In this paper, the effects of load ratio and maximum fatigue load on the fatigue response of adhesively bonded joints were studied experimentally and numerically. Single lap joints were tested under fatigue loading at different load ratios and maximum load levels. A numerical model that accounts for the load ratio effect was developed and validated against the experimental results to predict the fatigue response of adhesively bonded joints.

\section{Experimental Work}

Single lap joints (SLJ) were manufactured and tested under static and fatigue loading. In these joints, aluminium 2024-T3 substrates were bonded with FM 73M OST toughened epoxy film adhesive. The substrates were pre-treated prior to bonding. This pre-treatment consisted of a chromic acid etch (CAE) and phosphoric acid anodise (PAA) followed by the application of BR 127 corrosion inhibiting primer to maximise environmental resistance and bonding durability. The joints were cured at $120^{\circ} \mathrm{C}$ and under $\sim 0.28 \mathrm{MPa}$ pressure for 60 minutes. The dimensional details of the SLJ are shown in Fig. 1. The overlap length, the width and the thickness of the bond line were $30 \mathrm{~mm}, 12.5 \mathrm{~mm}$ and $0.2 \mathrm{~mm}$, respectively.

Fig. 1. The dimensional details of the single lap joint and the location of the attached strain gauges

The SLJs were tested under static and fatigue loading and two strain gauges were attached to the substrates at $1 \mathrm{~mm}$ inside the overlap (see Fig. 1). These backface strain gauges provided an independent measure of damage propagation that was used to validate the models developed. The strain gauges used in this research were FLA-1-23 (Techni Measure, UK) with $1 \mathrm{~mm}$ gauge length and a resistance of $120 \Omega$. The surface beneath the gauges was 
prepared before attaching the gauges using an abrasive paper (grade 240) and M-prep conditioner A (a water based acidic surface cleaner) from Vishay followed by neutralising with M-prep neutraliser 5A (a water based Alkaline surface cleaner) from Vishay measurement group and cotton wool buds. Then, the gauges were bonded on the prepared area using a cyanoacrylate adhesive.

The static strengths were measured by performing six static tests and an average value of $10.34 \mathrm{kN}$ with a standard deviation of $0.22 \mathrm{kN}$ was obtained. Fatigue tests were conducted at different load levels based on the average static strength and at load ratios of $R=0.1$ and 0.5 . The load-life curves obtained from the fatigue tests for $R=0.1$ and 0.5 are shown in Fig. 2.

Fig. 2. Experimental load-life fatigue data for the SLJ bonded with adhesives FM 73M OST and AV119 [1] for $R=0.1$ and 0.5

The maximum fatigue load, $P_{\max }$, of the SLJ bonded with the adhesive FM 73M OST, normalised by the static failure load, $P_{\mathrm{s}}$, is plotted against the fatigue life for $R=0.1$ and 0.5 and compared with the load-life curves obtained for SLJ bonded with the adhesive AV119 [1]. It is evident from Fig. 2 that the fatigue responses of the single lap joints were dependent on the load ratio. However, the degree of dependency can vary with different adhesive systems. A horizontal line on Fig. 2 can be used to find the fatigue life obtained for a certain maximum fatigue load and different load ratios. For instance, by maintaining $P_{\max }=0.5 P_{\mathrm{s}}$ and increasing the load ratio from 0.1 to 0.5 , the fatigue life of the SLJ bonded with the adhesive AV119 increased by a factor of 5, while for the adhesive FM 73M OST the life increased by a factor of over 50. This indicates a higher dependency of the adhesive FM 73M OST in comparison with the adhesive AV119 to the load ratio. The extrapolated load-life data point 
was used for the adhesive FM 73M OST at $R=0.5$ and $P_{\max }=0.5 P_{\mathrm{s}}$ for calculating the increase in fatigue life resulting from changing the load ratio from 0.1 to 0.5 (see Fig. 2).

Typical fracture surfaces for fatigue tested FM 73M OST SLJ are shown in Fig. 3. It can be seen that the failure was cohesive, running either fully within the adhesive layer or close to the interface. It can be seen that with lower maximum fatigue loads, the region of nearinterfacial failure increased. This is possibly because as the damage evolution is slower in the low load case there is a longer time for localised damage to take place during the longer cyclic life. It should be noted that in Fig. 3 only half of the failure surfaces are shown.

Fig. 3. Failure surfaces of single lap joint at $R=0.1$ and 0.5 and different load levels

Fatigue damage in adhesively bonded joints can be monitored using different techniques, e.g. backface strain, in-situ video microscopy, specimen sectioning, SEM and residual strength techniques. In this study, the backface strain technique was used to monitor the fatigue damage in the adhesive bond line. In the backface strain technique, which is a non-destructive method, strain gauges are bonded on the backface of the substrate, near a site of anticipated damage and, while the test is running, the strain variation is recorded. This variation of strain can be linked to the onset and growth of the damage. This is because damage initiation and propagation directly influence the deformation of the substrates and consequently cause variations in the strain. The backface strain technique was initially employed by Abe and Satoh [9] to study crack initiation and propagation in welded structures. Later, other authors [6,10-16] applied this technique to adhesively bonded joints. Numerical analyses were carried out to find the optimum position of the strain gauge. In this work, one strain gauge was attached $1 \mathrm{~mm}$ inside the overlap on both sides of the substrates (See Fig. 1). Fig. 4 shows the backface strain variations for SLJ under fatigue loading at load ratios of 0.5 and 0.1 and 
maximum fatigue loads of $75 \%$ and $50 \%$ of static strength, respectively. These two fatigue loading conditions gave reasonably similar fatigue lives.

Fig. 4. The variation of the measured backface strains in the SLJ: (a) for $R=0.5$ and $P_{\max }=0.75 P_{\mathrm{s}}$ and (b)

$$
\text { for } R=0.1 \text { and } P_{\max }=0.5 P_{\mathrm{s}}
$$

The backface strain history obtained from the fatigue tests can be divided into three regions as shown in Fig. 4. In region I, the backface strain changes were small indicating damage initiation. Then, in region II, the backface strain in both the gauges (SG1 and SG2) increased signifying that damage evolved symmetrically from both overlap ends. Finally, in region III, the strain value rapidly increased on one of the strain gauges and reduced on the other one. This trend indicates that the damage evolution accelerated at the end with decreasing strain. This backface strain reduction is due to a local deformation relaxation at the location of the strain gauge as crack passes under the strain gauge position. Moreover, it is evident from Fig. 4 that at the lower load ratio the stable crack growth phase (region II) was relatively shorter and the unstable crack growth phase (region III) was relatively longer.

\section{Finite Element Modelling}

\subsection{Static modelling}

A finite element model, shown in Fig. 5, was developed in Abaqus/Standard to predict the static behaviour of the single lap joint. Initially, two-dimensional static failure analyses based on plane stress and plane strain assumptions were performed and both were compared with a three-dimensional static failure analysis. The comparison between 3D and 2D analyses revealed that the plane stress assumption predicted the static failure load more accurately and thus was used in subsequent analyses. Four-node plane stress elements (CPS4) were used for the substrates and four-node cohesive elements (COH2D4) with a bi-linear traction-separation 
response were utilised to study the progressive damage in the adhesive bond line. The boundary conditions used are shown in Fig. 5. The left boundary of the upper substrate was encastre. The transverse displacement and the rotation at the right boundary of the lower substrate were constrained. To obtain more accurate results, a higher mesh density was used for the adhesive bond line (cohesive zone) elements. The size of the cohesive element was $0.2 \times 0.2 \mathrm{~mm}$ throughout the adhesive bond line. More detailed information about this static model can be found in Ref. [17].

Fig. 5. Finite element mesh and boundary conditions

Currently, the cohesive zone model (CZM) is considered to be the most efficient and reliable method for simulating the progressive damage in the adhesively bonded joints. This model was developed in a continuum damage mechanics framework and made use of fracture mechanics concepts to improve its applicability. Some of the main advantages of the CZM over other methods, including fracture mechanics, continuum damage mechanics, stress singularity based and total-life approaches, are:

- indicating both damage onset and growth as direct outputs of the method,

- predicting the behaviour of uncracked materials without the need to introduce a preexisting crack,

- advancing the crack front when the local energy release rates reach a critical value without the need to implement complex moving mesh techniques,

- considering finite stress and strain at the crack front and consequently avoiding the need of using singular elements and/or highly refined mesh around the crack front.

The basic idea of the CZM originated from the observation that as the distance between two atomic planes within the material or at the interface increases the cohesion forces initially 
grow in intensity, reach a maximum value and then any further separation will result in a rapid decrease of the intensity. The effect of mode-mixity can be incorporated in the cohesive zone model by combining individual traction-separation responses in peel and shear. A schematic of a mixed-mode bi-linear traction-separation description of the cohesive zone model is shown in Fig. 6. Note that the initial response is stiff until a critical traction condition is reached. Following this point the material softens with increasing displacement until the failure point is reached, where no load can be sustained. The area under the tractiondisplacement curve is the fracture energy. The bi-linear traction-separation responses under peel, shear and mixed-mode stress states are illustrated in Fig. 6. The mixed-mode response, depending on the mode mixity, can be closer either to the response of mode I or mode II. Damage initiation (point A) and propagation (point B) have been defined based upon mixedmode damage initiation and propagation criteria, respectively.

Fig. 6. Mixed-mode bi-linear traction-separation law

The defining parameters of the mixed-mode traction-separation response are: (a) the fracture energies for mode I and mode II ( $G_{\mathrm{IC}}$ and $\left.G_{\mathrm{IIC}}\right)$, (b) the tripping tractions for mode I and mode II $\left(\mathrm{T}_{\mathrm{I}}\right.$ and $\left.\mathrm{T}_{\mathrm{II}}\right)$, (c) the initial stiffnesses for mode-I and mode-II $\left(\mathrm{E}_{\mathrm{I}}\right.$ and $\left.\mathrm{E}_{\mathrm{II}}\right)$ and (d) the mixedmode criteria for both damage initiation and propagation. These parameters are explained in more detail elsewhere [7].

\subsection{Calibration of cohesive parameters}

To model adhesively bonded joints using the CZM, the cohesive zone parameters, which define the adhesive bond line response, need to be calibrated. Considering only the static strength of the adhesively bonded joints cannot give an accurate and unique set of cohesive 
zone parameters as different sets of cohesive zone parameters can predict the same static strength. This is shown in Fig. 7.

Fig. 7. The effects of the fracture energy and tripping traction on the static failure load

In Fig. 7, the effects of the fracture energy and tripping traction on the static failure load are shown schematically. It is evident that increasing the fracture energy or the tripping traction increases the predicted failure load. Furthermore, although different sets of fracture energies and tripping tractions, e.g. $\left(G_{1}, T_{1}\right),\left(G_{2}, T_{2}\right)$ and $\left(G_{3}, T_{3}\right)$ in Fig. 7 , can predict the same static strength, only one set will be physically acceptable.

The variation of the backface strain with applied load during a static failure test implicitly represents the combined state of adhesive and substrate yielding and adhesive damage initiation and propagation. In this study, a unique, physically acceptable set of cohesive zone parameters have been calibrated using the experimentally obtained backface strain history from the static tests on the single lap joint. The predicted static strength and the progressive damage evolution from the cohesive zone model were compared against the respective experimentally measured results. The backface strain variation was utilised as a measure of the progressive damage evolution. The predicted backface strains from two sets of parameters are compared with the experimental data in Fig. 8, where normalised load versus normalised backface strain data are used.

Fig. 8. The effect of the cohesive zone parameters on the predicted backface strain (BFS) variation 
The two predicted curves obtained from two sets of cohesive zone parameters are shown in Fig. 8. The first set, denoted as $\mathrm{CZM}_{1}$, has fracture energies of $1.4 \mathrm{~kJ} / \mathrm{m}^{2}$ and $2.8 \mathrm{~kJ} / \mathrm{m}^{2}$ in mode I and II and tripping tractions of $114 \mathrm{MPa}$ and $66 \mathrm{MPa}$ in mode I and II respectively. The second set, denoted as $\mathrm{CZM}_{2}$, has fracture energies of $2 \mathrm{~kJ} / \mathrm{m}^{2}$ and $4 \mathrm{~kJ} / \mathrm{m}^{2}$ in mode I and II and tripping tractions of $65 \mathrm{MPa}$ and $38 \mathrm{MPa}$ in mode I and II respectively. Although the two sets $\left(\mathrm{CZM}_{1}\right.$ and $\left.\mathrm{CZM}_{2}\right)$ predicted the static failure load accurately, the predicted backface strain variations are quite different beyond a certain load level (see Fig. 8). The second set of cohesive parameters $\left(\mathrm{CZM}_{2}\right)$ predicted both the static failure load and the backface strain (the damage evolution) accurately and thus have been used in the subsequent modelling.

To validate the proposed method, standard fracture mechanics tests were carried out using the double cantilever beam (DCB) to determine the fracture toughness of the 2024-T3 and FM 73M OST adhesive system (using the same surface preparation as used in the SLJs). A range of fracture energy values ( 2.0 to $2.5 \mathrm{kJm}^{-2}$ ) was obtained. This is in good agreement with the second set $\left(\mathrm{CZM}_{2}\right)$ obtained from the backface strain technique.

The effects of different damage initiation and growth criteria and the interaction of mesh size, tripping tractions and fracture energies on the static strength were further investigated. It was found that the second set $\left(\mathrm{CZM}_{2}\right)$, along with the maximum nominal stress criterion for damage initiation and the Benzeggagh-Kenane [18] mixed-mode criterion for damage evolution, accurately predicted both the static failure load and the backface strain variation. The cohesive zone parameters and the damage initiation and propagation criteria are summarised in Table 1. 
Table 1. Calibrated traction-separation response

Tripping traction Fracture energies

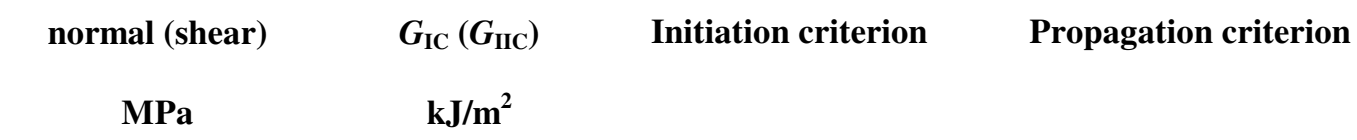

$65(38)$

Maximum nominal Benzeggagh-Kenane (BK)

stress criterion (with $\eta=2$ )

The Maximum nominal stress criterion (Eq. 1) signifies that damage is assumed to initiate when either the peel or shear component of traction $\left(t_{I}\right.$ or $\left.t_{I I}\right)$ exceeds the respective critical value $\left(T_{I}\right.$ or $\left.T_{I I}\right)$.

$\max \left\{\frac{\left\langle t_{I}\right\rangle}{T_{I}}, \frac{t_{I I}}{T_{I I}}\right\}=1$

in which \langle\rangle is the Macaulay bracket meaning that the compression stress state does not lead to the damage initiation. The Benzeggagh-Kenane (BK) criterion is defined in Eq. 2.

$G_{I}^{C}+\left(G_{I I}^{C}-G_{I}^{C}\right)\left(\frac{G_{I I}}{G_{I}+G_{I I}}\right)^{\eta}=G_{I}+G_{I I}$

where $G_{\mathrm{I}}$ and $G_{\mathrm{II}}$ are the energies released by the traction due to the respective separation in normal and shear directions, $G_{I}^{C}$ and $G_{I I}^{C}$ are the critical fracture energies required for failure in the normal and shear directions, respectively and $\eta$ is a material parameter.

A static strength of $10.28 \mathrm{kN}$ was predicted using the calibrated traction-separation response which was in excellent correlation with the experimentally measured value of $10.34 \pm 0.22$ $\mathrm{kN}$. Furthermore, the traction-separation response obtained using these parameters operated in the mesh independent region, in accordance with the Liljedahl et al. [19] study. They investigated the interaction of the tripping traction value and the FE mesh density on the 
failure load and divided the tripping traction range into three regions: low, intermediate and high. They found that using the traction-separation response in the high region is not acceptable because the results are mesh dependent and represent a discontinuous process zone.

\subsection{Fatigue}

The validated static model developed in Section 3.2 is now extended to model the fatigue failure of the single lap joint. To predict the effect of load ratio and maximum fatigue load of the adhesively bonded joint, a cyclic fatigue damage parameter was incorporated into the model. The traction-separation response was degraded based on this fatigue damage parameter, which evolved during the fatigue cycles based on a fatigue damage evolution law (Eq. 3). The evolution of fatigue damage is a function of the maximum principal strain, the number of fatigue cycles, the load ratio, the maximum fatigue load and the adhesive threshold strain. This cyclic fatigue damage law has been introduced in an earlier study [7] for a fixed load ratio. Here it has been extended to accommodate any load ratio.

$$
\begin{gathered}
\frac{\Delta D}{\Delta N}= \begin{cases}\alpha\left[\left(\varepsilon_{\max }-\varepsilon_{t h}\right) \gamma^{n}\right]^{\beta}, & \varepsilon_{\text {max }}>\varepsilon_{t h} \\
0, & \varepsilon_{\text {max }} \leq \varepsilon_{t h}\end{cases} \\
\gamma=\frac{(1-R) / 2}{1-\left[\frac{P_{\max }}{2 P_{S}}(1+R)\right]^{m},}, \begin{array}{l}
m=1, \text { Goodman } \\
m=2, \text { Gerber }
\end{array}
\end{gathered}
$$

The fatigue damage evolution law is given in Eq. 3, in which $\Delta D$ is the increment of damage, $\Delta N$ is the cycle increment, $\varepsilon_{\max }$ is the maximum principal strain in the cohesive element, $\varepsilon_{t h}$ 
is the threshold strain and $\alpha, \beta, m$ and $n$ are material constants. $R$ is the load ratio and $P_{\max }$ and $P_{\mathrm{S}}$ are the maximum fatigue load and the static strength, respectively. The parameters $\varepsilon_{\mathrm{th}}, \alpha$, $\beta, m$ and $n$ need to be calibrated against the experimental tests to predict the fatigue failure response of the bonded joints. Increasing the value of $\beta$ and the threshold strain $\left(\varepsilon_{t h}\right)$ decelerate the damage evolution and increase the lifetime, while increasing the constant $\alpha$ accelerates the damage evolution and consequently decreases the predicted fatigue lifetime. Furthermore, changing the constant $\alpha$ leads to a shift of the load-life (P-N) curve in the horizontal direction ( $\mathrm{N}$-direction). However, increasing $\beta$ decreases the slope of the P-N curve by decelerating the fatigue damage more at lower strain (load) levels. This is due to the fact that the strains in the adhesive bond line are small $(<1)$ and thus at lower fatigue load levels they reduce more rapidly with the power $\beta$ (when $\beta>1$ ). The parameter $n$ is introduced to accommodate the ductility of the adhesive and it will be seen that the FM 73M OST adhesive, which is more ductile, requires a larger value of $n$ than the adhesive AV119, which is more linear.

In this fatigue model, a fatigue damage variable was introduced into the model at each element integration point. This variable was updated according to the strain-based fatigue damage law (Eq. 3) for each cycle increment $(\Delta N)$. The initial Young's modulus, the tripping tractions and the fracture energies of the cohesive elements were reduced based on this damage variable. The fatigue loading was characterised by a constant load equal to the maximum fatigue load and the effect of load ratio was included by incorporating a correction factor, $\gamma\left(P_{\max }, R\right)$, in the fatigue damage evolution law (Eq. 3). This correction factor, dependent on the adhesive material, was derived based on the linear Goodman or parabolic Gerber equations (Eq. 4). 


$$
\frac{P_{a}}{\overline{P_{a}}}+\left(\frac{P_{m}}{P_{s}}\right)^{m}=1, \quad \begin{aligned}
& m=1, \text { for Goodman } \\
& m=2, \text { for Gerber }
\end{aligned}
$$

In Eq. 4, $P_{\mathrm{a}}$ and $P_{\mathrm{m}}$ are the load amplitude and mean fatigue load, respectively, and $\overline{P_{a}}$ is the equivalent load amplitude at $R=-1$ (fully reversed), that has the same fatigue life as the arbitrary fatigue loads $P_{\mathrm{a}}$ and $P_{\mathrm{m}} . P_{\mathrm{s}}$ is the ultimate static strength of the bonded joint. The Goodman and Gerber diagrams are shown in Fig. 9. Lines on these constant-life diagrams represent all possible combinations of the load amplitude and mean fatigue load that have the same fatigue life.

Fig. 9. Goodman and Gerber empirical expressions of the load ratio effect on fatigue life.

Dependent on the adhesive material, an empirical constant-life curve can be fitted to the experimental data. Fig. 10 shows the constant-life data for single lap joints bonded with the adhesives AV119 [1] and FM 73M OST having a fatigue life of $10^{5}$ cycles. It is expected that when the fatigue amplitude $\left(P_{\mathrm{a}}\right)$ is zero the mean load $\left(P_{\mathrm{m}}\right)$ must equal the static strength for failure to occur. It is evident that the experimental results for the adhesive FM 73M OST correlated well with the Gerber diagram, whereas those for the adhesive AV119 correlated well with the Goodman diagram. Therefore, the Goodman equation was used to derive the correction factor for the adhesive AV119 and the Gerber equation was utilised for the adhesive FM 73M OST. It is worth mentioning that no extra experimental data are required to chose the appropriate constant-life curve as this can be determined using the experimental results needed to determine other fatigue damage model parameters.

Fig. 10. Constant-life diagrams for adhesives FM 73M OST and AV119 
The constant-life curves can represent the degree of dependency of the fatigue life to the loading conditions (i.e. mean and amplitude loads). The constant-life curve for adhesive FM 73M OST which follows the Gerber diagram indicates that this adhesive is less sensitive to the mean load and more sensitive to the amplitude load. Conversely, the constant-life curve for the adhesive AV119 which follows the Goodman diagram shows that this adhesive is relatively less sensitive to the amplitude load and more sensitive to the mean load.

By solving Eq. (4) for $\overline{P_{a}}$ and substituting $P_{a}$ and $P_{m}$ with $P_{\max }(1-R) / 2$ and $P_{\max }(1+R) / 2$ respectively, Eq. (5) can be obtained.

$$
\begin{array}{ll}
\overline{P_{a}}=P_{\max } \gamma & \\
\gamma=\frac{(1-R) / 2}{1-\left[\frac{P_{\max }}{2 P_{S}}(1+R)\right]^{m}}, & m=1, \text { for Goodman }
\end{array}
$$

Any combination of $P_{a}$ and $P_{m}$ on the constant-life diagrams (Goodman or Gerber) can be projected to the corresponding fully reversed $(\mathrm{R}=-1)$ load point (e.g. point A in Fig. 9) by multiplying its maximum fatigue load with the corresponding correction factor $\gamma$. This correction factor was utilised in the proposed fatigue damage model to account for the effect of load ratio. This fatigue damage model is illustrated in a flowchart form in Fig. 11.

Fig. 11. The flowchart of the fatigue damage model in Abaqus/Standard

A load equal to the maximum fatigue load was applied to the model and FE analysis was performed with intact material properties. The maximum principal strain was obtained from the finite element analysis results for each cohesive element and the damage increment was 
calculated based on the damage evolution law (Eq. 3), which is a function of the fatigue cycles, the maximum principal strain, the threshold strain, the load ratio and the maximum fatigue load. In this expression the strains have been modified by the correction factor to produce "equivalent" fully reversed strains. The traction-separation response (initial Young's moduli, tripping tractions and fracture energies) was degraded linearly to zero based on the fatigue damage variable (see Eq. 6) and the analysis was repeated using the newly degraded material properties.

$\zeta=\zeta_{0}(1-D)$

In Eq. $6, \zeta$ and $\zeta_{0}$ are degraded and intact traction-separation properties (i.e. initial Young's moduli, tripping tractions and fracture energies), respectively. The material degradation process discussed above was repeated until the damaged joint could no longer sustain the applied maximum fatigue load, at which point the joint fails.

A parametric study was undertaken to assess the effect of the fatigue damage model parameters on the fatigue response of the bonded joints. With this information an informed iterative approach was undertaken to determine appropriate fatigue damage model parameter values (summarised in Table 2) that matched the fatigue response of the joints. The effects of the parameters $\alpha, \beta$ and $\varepsilon_{\mathrm{th}}$ on the fatigue response of the bonded joints were discussed earlier. Moreover, the parameter $m$ can be determined from the constant life curves (Fig. 10) and the parameter $n$ represents the degree of sensitivity of the adhesive system to the load ratio. The parameter $n$ was considered as 4 and 1 for the adhesives FM 73M OST and AV119, respectively. This is consistent with the experimental fatigue results as it was observed that 
the adhesive FM 73M OST was significantly more sensitive to the load ratio than the adhesive AV119 (see Fig. 2).

Table 2. The fatigue damage model parameters

\begin{tabular}{cccccc} 
Adhesive & $\boldsymbol{\alpha}$ & $\boldsymbol{\beta}$ & $\boldsymbol{\varepsilon}_{\text {th }}$ & $\mathbf{m}$ & $\mathbf{n}$ \\
\hline FM 73M OST & 95 & 2 & 0.0265 & 2 (Gerber) & 4 \\
AV119 & 16 & 2 & 0.02 & 1 (Goodman) & 1
\end{tabular}

A simplified version of this fatigue model in conjunction with the CZM was initially employed by Khoramishad et al. [7]. Further Katnam et. al. [8] extended the model in a preliminary attempt to incorporate the load ratio effect. Although this model performed well for the adhesive AV119, it failed to predict the load ratio effect of the fatigue response of the current adhesive system (2024-T3 and FM 73M OST). This was because different adhesive systems exhibit different sensitivities to the variation of the load ratio. For instance, adhesive FM 73M OST was found to be much more sensitive to the load ratio variation than AV119 adhesive.

The fatigue failure responses of the single lap joints with 2 different adhesive systems, one with the FM 73M OST adhesive and aluminium 2024-T3 substrates and the other one with the adhesive AV119 and steel substrates [1], were predicted using the proposed fatigue damage model. The predicted load-life data correlated well with the experimental data, as shown in Fig. 12. The fatigue load has been expressed (normalised) as a fraction of the static failure load of the particular configuration. 
Fig. 12. Comparison between the experimental (data points) and numerical (curves) load-life results

Typical predicted and measured backface strain variations for the FM 73M OST single lap joints are compared in Fig. 13. The measured backface strain variation represents the damage evolution of the adhesive bond line. The correlation between the experimental and numerical backface strain data provided an independent validation of the damage model. As shown in Fig. 13, the predicted and measured backface strains are in good agreement signifying that the predicted damage evolution was consistent with the experimental damage evolution. It can be seen in Fig. 13 that the backface strain increased initially followed by a decrease. This backface strain reduction was due to a local stress relaxation at the location of the strain gauge as the crack passed under the strain gauge position.

Fig. 13. Comparison of the typical predicted and measured backface strain variations at $1 \mathrm{~mm}$ inside the overlap, $R=0.1$ and maximum fatigue load of $50 \%$ of static strength

\section{Conclusions}

The fatigue behaviour of adhesively bonded joints was investigated using both experimental and numerical approaches. Fatigue tests were conducted on single lap joints at different load ratios and maximum fatigue loads in order to study the effect of load ratio on the fatigue response. A numerical model that accounts for the load ratio effect was successfully developed using a cohesive zone approach with a bi-linear traction separation response for the adhesive bond line. The following conclusions were drawn: 
(a) A method for determining a physically acceptable set of cohesive zone parameters governing the static failure of an adhesive system has been presented. This is based on using both load and deformation (backface strain) data from a static test.

(b) Based on the fatigue tests conducted at two different load ratios ( $\mathrm{R}=0.1$ and 0.5$)$, the effect of load ratio on the fatigue failure was found to be significant for the 2024-T3 and FM 73M OST adhesive system. The load-life curves obtained for the two load ratio values revealed that a decrease in the load ratio value for a constant maximum fatigue load has a significantly adverse effect on the fatigue life.

(c) The load ratio effect observed for FM 73M OST was found to be much more significant than in another reported adhesive system (AV119). As far as the authors are aware these two systems are the only adhesive systems that have been characterised in this way.

(d) The developed numerical model accurately predicted the effect of load ratio on the fatigue lives of both the FM 73M OST and the AV119 single lap joints. Further, where the experimental data existed (FM 73M OST) it correlated well with the predicted adhesive fatigue damage initiation and propagation as well.

\section{References}

[1] A.D. Crocombe, G. Richardson, Assessing stress state and mean load effects on the fatigue response of adhesively bonded joints, International Journal of Adhesion and Adhesives 19 (1999) 19-27.

[2] H. Elkadi, F. Ellyin, Effect of Stress Ratio on the Fatigue of Unidirectional Glass-Fiber Epoxy Composite Laminae, Composites 25 (1994) 917-924. 
[3] J.F. Mandell, U. Meier, Effects of stress ratio, frequency, and loading time on the tensile fatigue of glass-reinforced epoxy, Long-Term Behavior of Composites, Symposium, Williamsburg, VA, USA (1983) 55-77.

[4] P.R. Underhill, D.L. DuQuesnay, The dependence of the fatigue life of adhesive joints on surface preparation, International Journal of Adhesion and Adhesives 26 (2006) 6266.

[5] V. Shenoy, I.A. Ashcroft, G.W. Critchlow, A.D. Crocombe, Unified methodology for the prediction of the fatigue behaviour of adhesively bonded joints, International Journal of Fatigue 32 (2010) 1278-1288.

[6] A.G. Solana, A.D. Crocombe, I.A. Ashcroft, Fatigue life and backface strain predictions in adhesively bonded joints, International Journal of Adhesion and Adhesives 30 (2010) $36-42$.

[7] H. Khoramishad, A.D. Crocombe, K.B. Katnam, I.A. Ashcroft, Predicting fatigue damage in adhesively bonded joints using a cohesive zone model, International Journal of Fatigue 32 (2010) 1146-1158.

[8] K.B. Katnam, A.D. Crocombe, H. Khoramishad, I.A. Ashcroft, Load ratio effect on the fatigue behaviour of adhesively bonded joints: An enhanced damage model, The Journal of Adhesion 86 (2010) 257-272.

[9] H. Abe, T. Satoh, Non-destructive detection method of fatigue crack in spot-welded joints, Yosetsu Gakkai Ronbunshu/Quarterly Journal of the Japan Welding Society 4 (1986) 666-673.

[10] Z.H. Zhang, J.K. Shang, F.V. Lawrence, A Backface Strain Technique for Detecting Fatigue-Crack Initiation in Adhesive Joints, Journal of Adhesion 49 (1995) 23-36.

[11] M. Imanaka, K. Haraga, T. Nishikawa, Fatigue-Strength of Adhesive Rivet Combined Lap Joints, Journal of Adhesion 49 (1995) 197-209.

[12] A.J. Curley, H. Hadavinia, A.J. Kinloch, A.C. Taylor, Predicting the service-life of adhesively-bonded joints, International Journal of Fracture 103 (2000) 41-69.

[13] A.D. Crocombe, C.Y. Ong, C.M. Chan, M.M.A. Wahab, I.A. Ashcroft, Investigating fatigue damage evolution in adhesively bonded structures using backface strain measurement, Journal of Adhesion 78 (2002) 745-776.

[14] H. Hadavinia, A.J. Kinloch, M.S.G. Little, A.C. Taylor, The prediction of crack growth in bonded joints under cyclic-fatigue loading I. Experimental studies, International Journal of Adhesion and Adhesives 23 (2003) 449-461.

[15] G. Kelly, Quasi-static strength and fatigue life of hybrid (bonded/bolted) composite single-lap joints, Composite Structures 72 (2006) 119-129.

[16] A. Graner Solana, A.D. Crocombe, M.M.A. Wahab, I.A. Ashcroft, Fatigue initiation in adhesively-bonded single-lap joints, Journal of Adhesion Science and Technology 21 (2007) 1343-1357. 
[17] K.B. Katnam, A.D. Crocombe, H. Khoramishad, I.A. Ashcroft, The static failure of adhesively bonded metal laminate structures: A cohesive zone approach, Submitted to Journal of Adhesion Science and Technology (2009).

[18] M.L. Benzeggagh, M. Kenane, Measurement of mixed-mode delamination fracture toughness of unidirectional glass/epoxy composites with mixed-mode bending apparatus, Composites Science and Technology 56 (1996) 439-449.

[19] C.D.M. Liljedahl, A.D. Crocombe, M.A. Wahab, I.A. Ashcroft, Damage modelling of adhesively bonded joints, International Journal of Fracture 141 (2006) 147-161. 


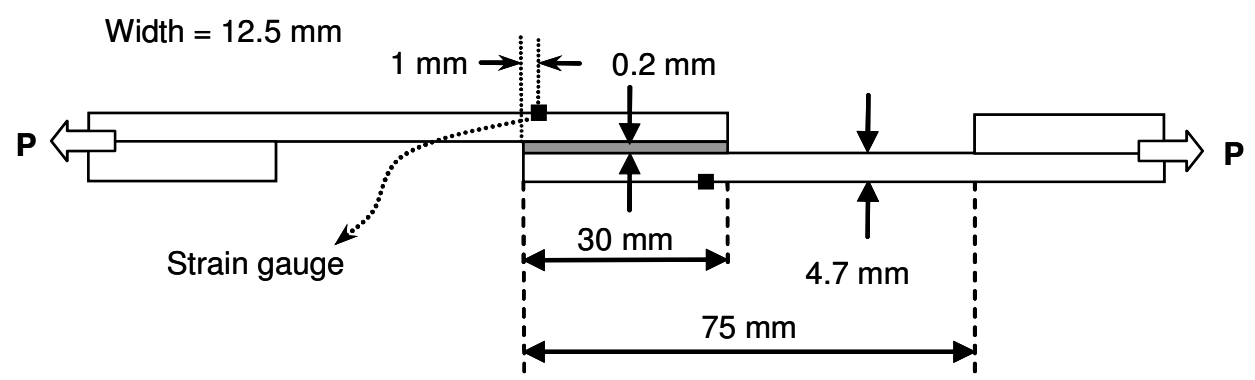

Fig. 1. The dimensional details of the single lap joint and the location of the attached strain gauges 


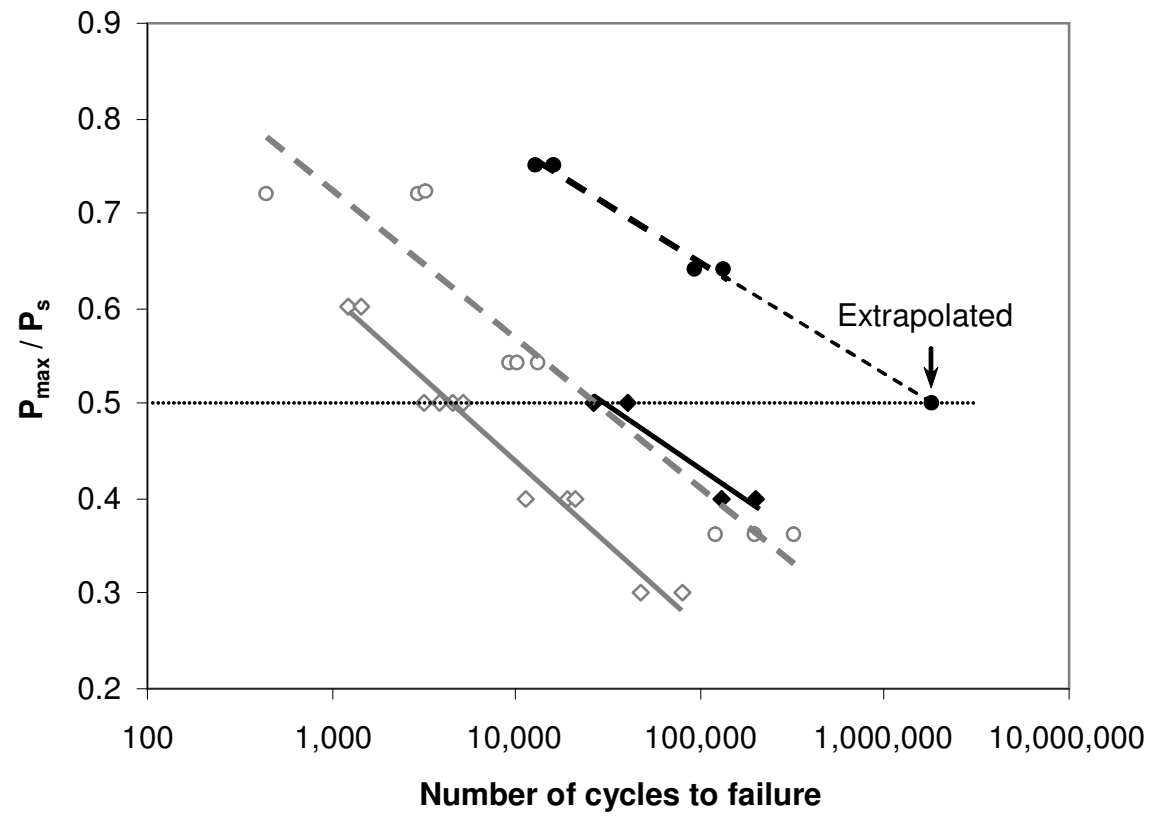

$\leadsto$ FM 73M OST, $R=0.1 \leadsto A V 119, R=0.1$

$\rightarrow-$ FM 73M OST, R=0.5 $-A-A V 119, R=0.5$

Fig. 2. Experimental load-life fatigue data for the SLJ bonded with adhesives FM 73M OST and AV119

[1] for $R=0.1$ and 0.5 
$\mathrm{R}=0.1$

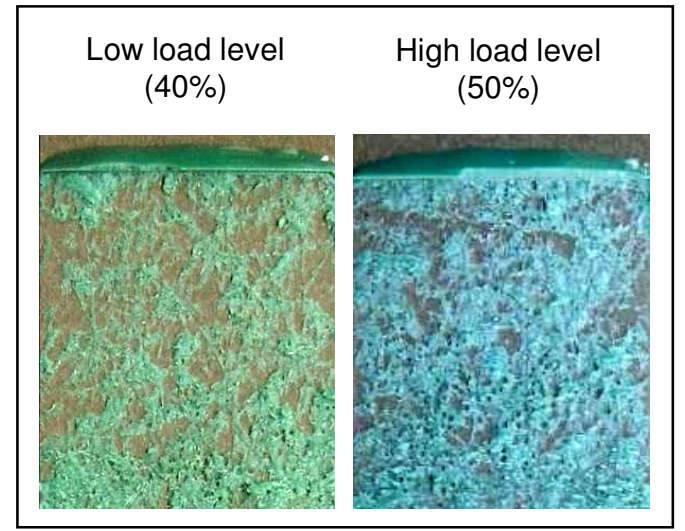

$\mathrm{R}=0.5$

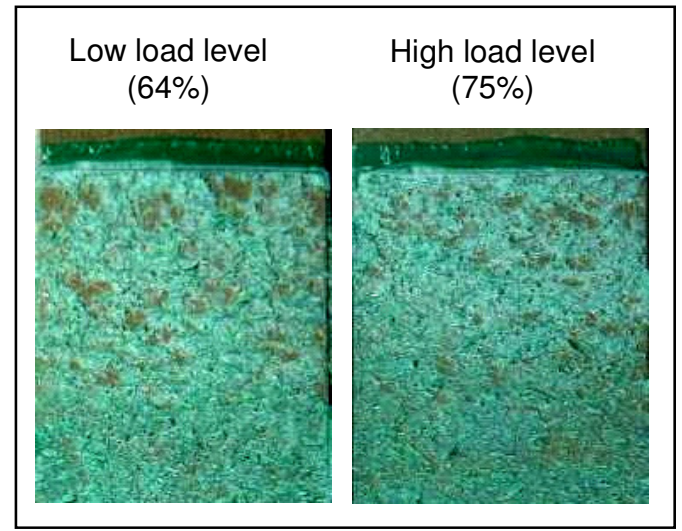

Fig. 3. Failure surfaces of single lap joint at $R=0.1$ and 0.5 and different load levels (Note the decreasing amount of failure close to the interface from left to right) 

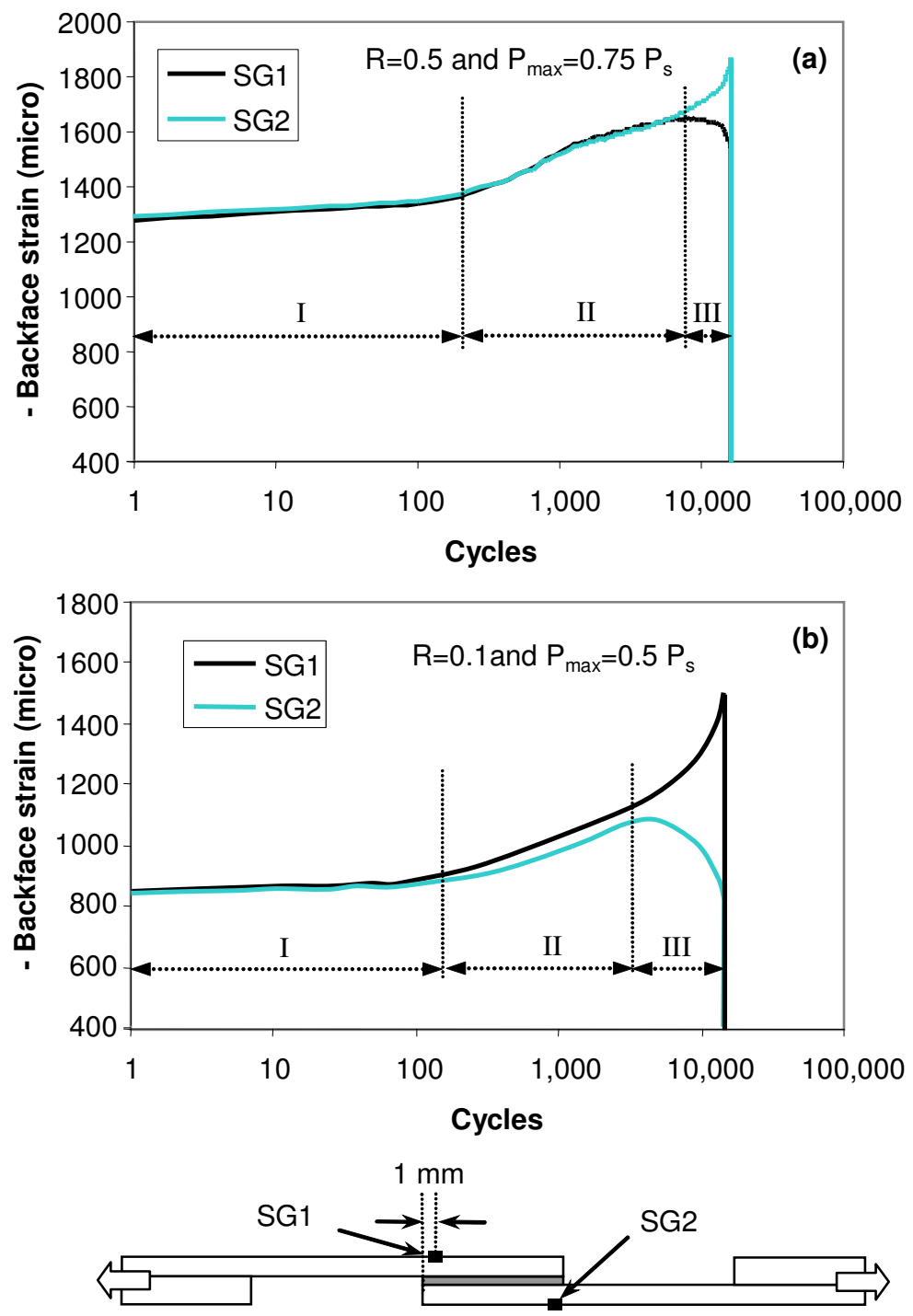

Fig. 4. The variation of the measured backface strains in the SLJ: (a) for $R=0.5$ and $P_{\max }=0.75 P_{\mathrm{s}}$ and (b) for $\boldsymbol{R}=0.1$ and $\boldsymbol{P}_{\max }=0.5 \boldsymbol{P}_{\mathrm{s}}$ 


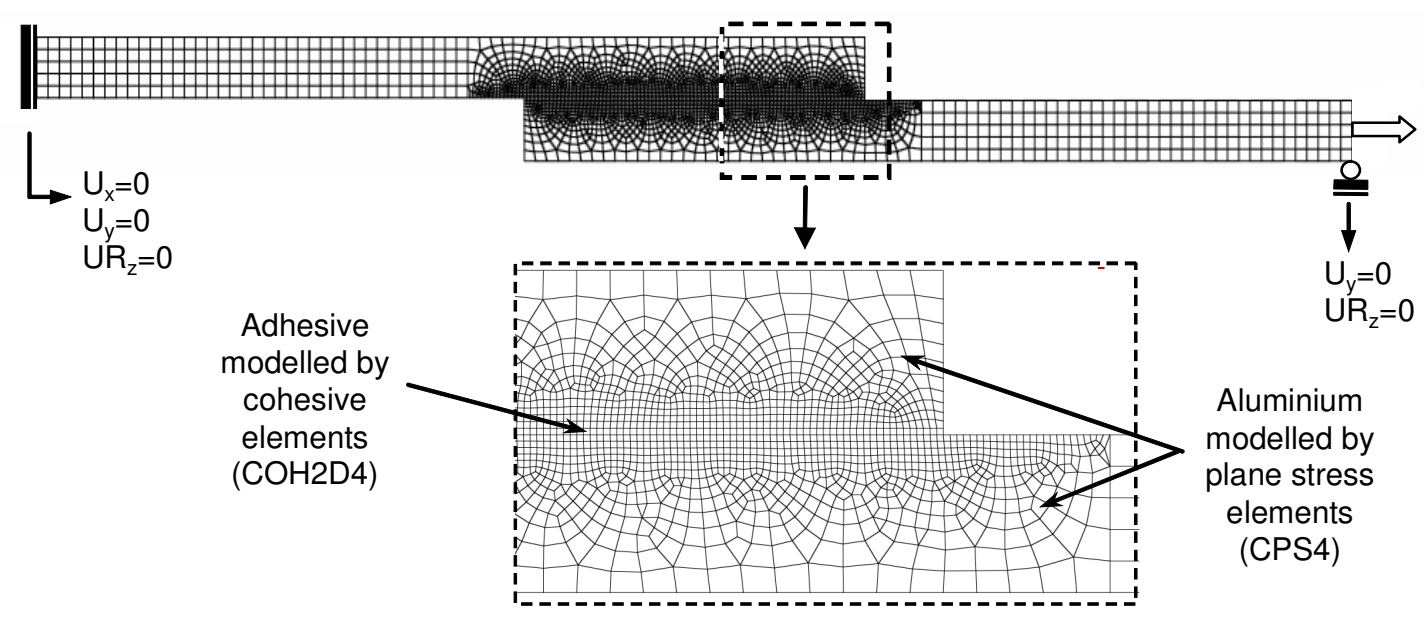

Fig. 5. Finite element mesh and boundary conditions 


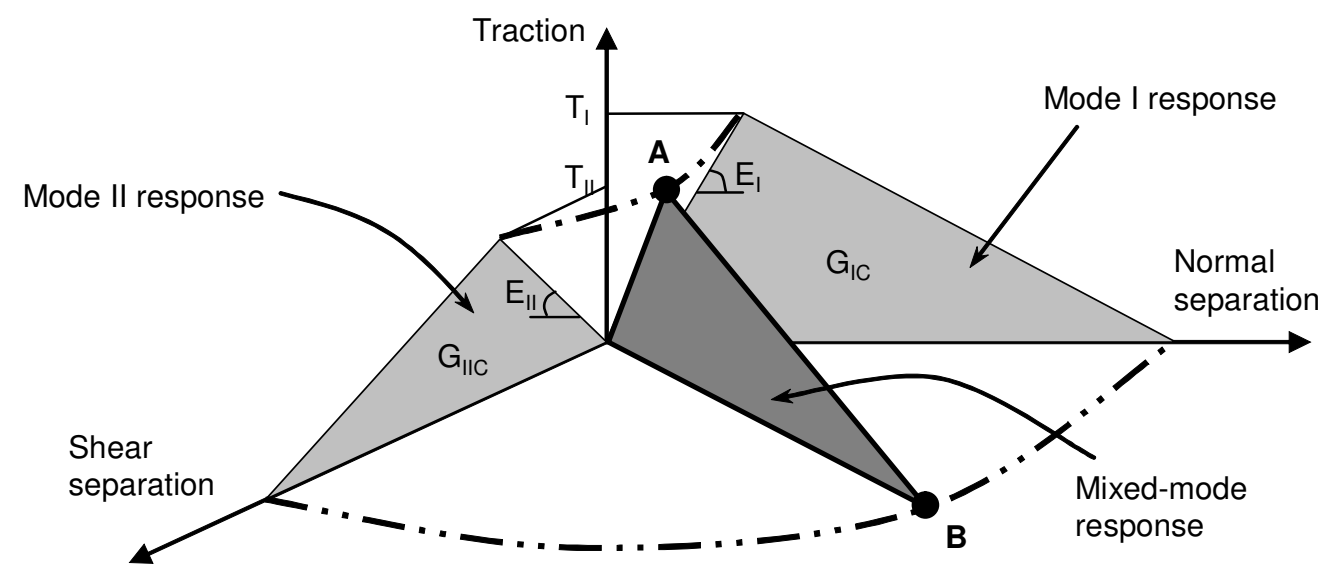

- - Damage initiation criterion

- $\cdots$ - Damage propagation criterion

Fig. 6. Mixed-mode bi-linear traction-separation law 


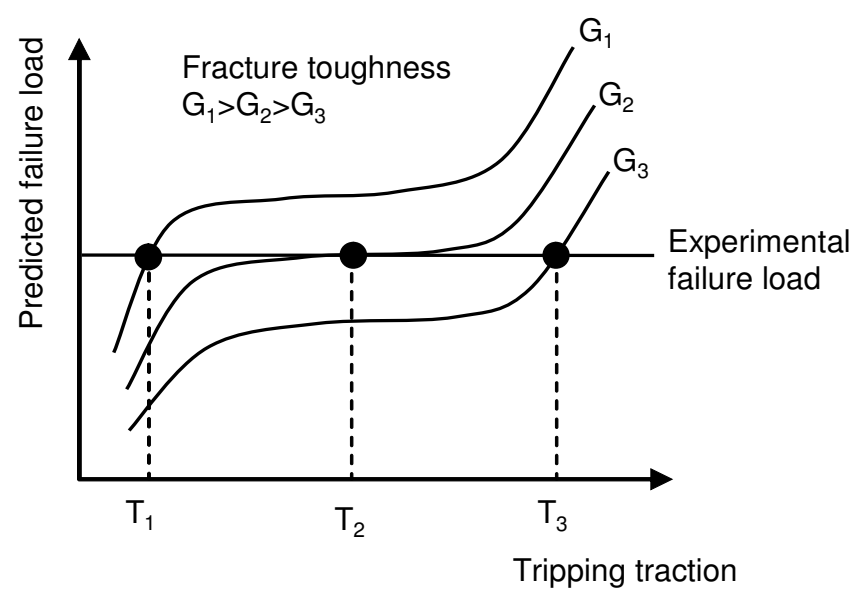

Fig. 7. The effects of the fracture energy and tripping traction on the static failure load 


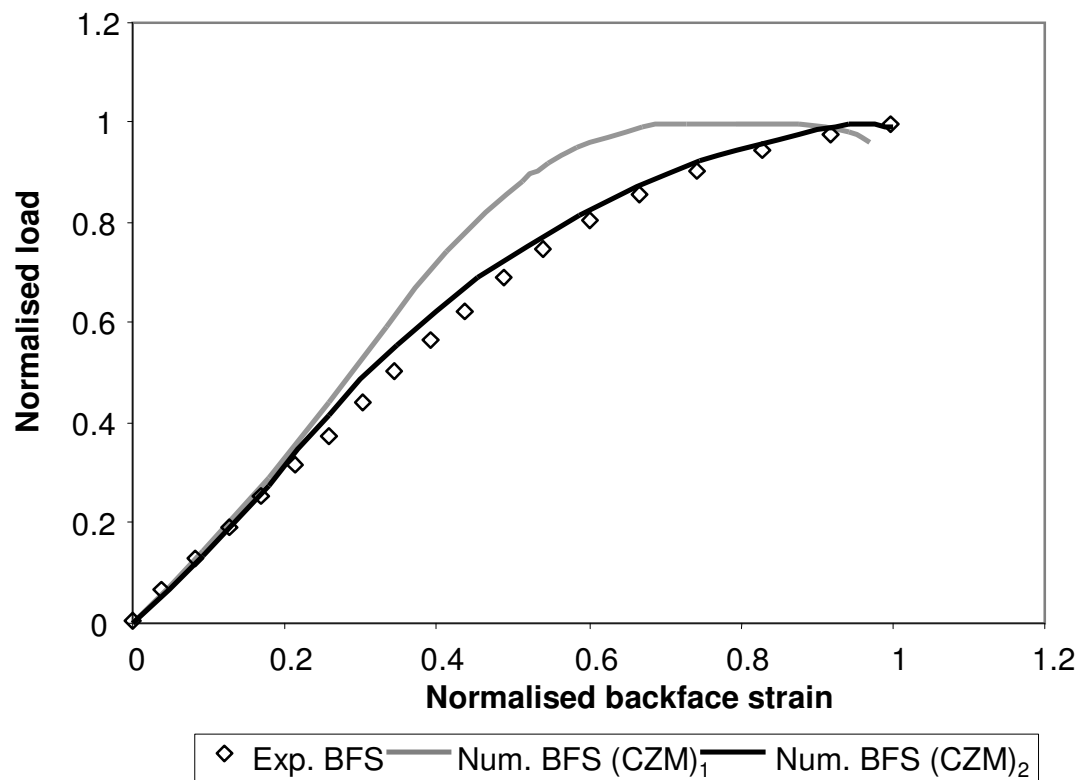

Fig. 8. The effect of the cohesive zone parameters on the predicted backface strain (BFS) variation 


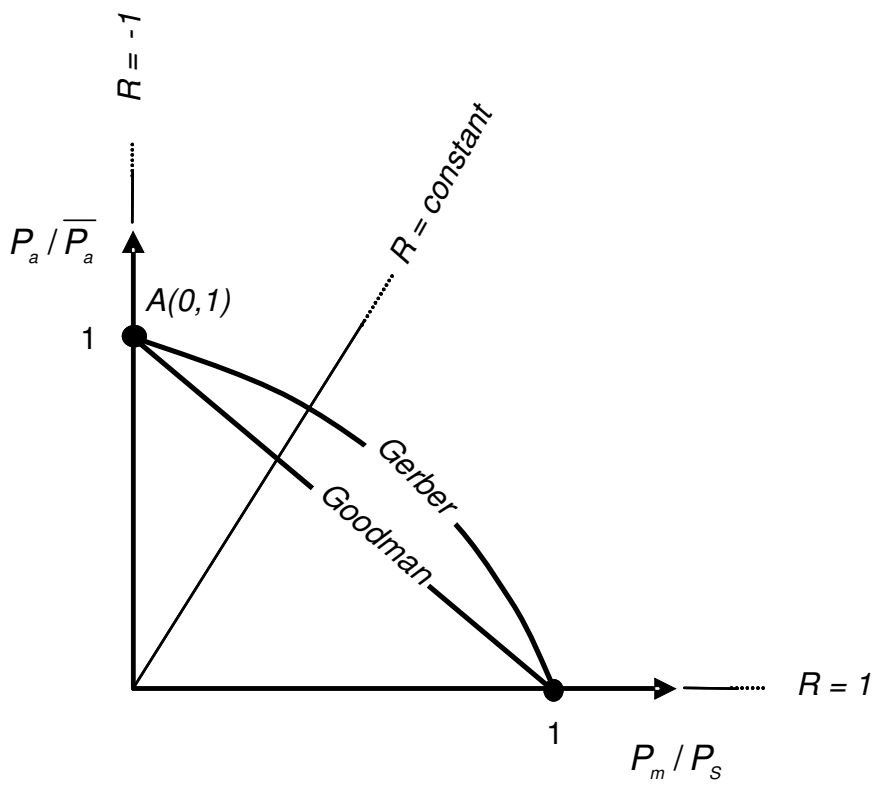

Fig. 9. Goodman and Gerber empirical expressions of the load ratio effect on fatigue life. 


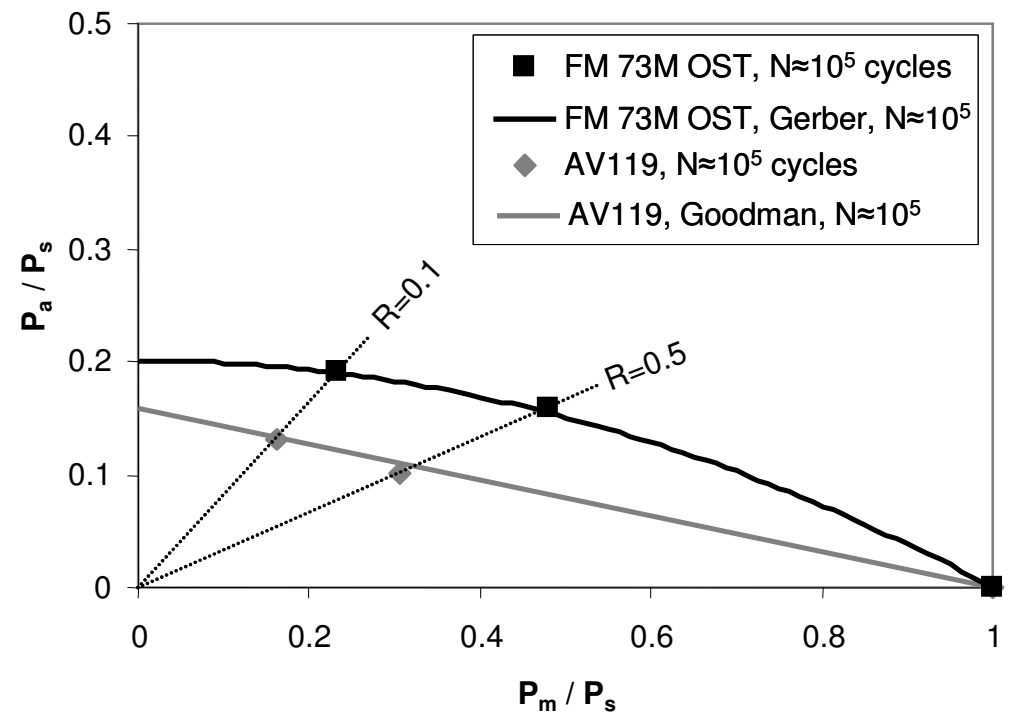

Fig. 10. Constant-life diagrams for adhesives FM 73M OST and AV119 


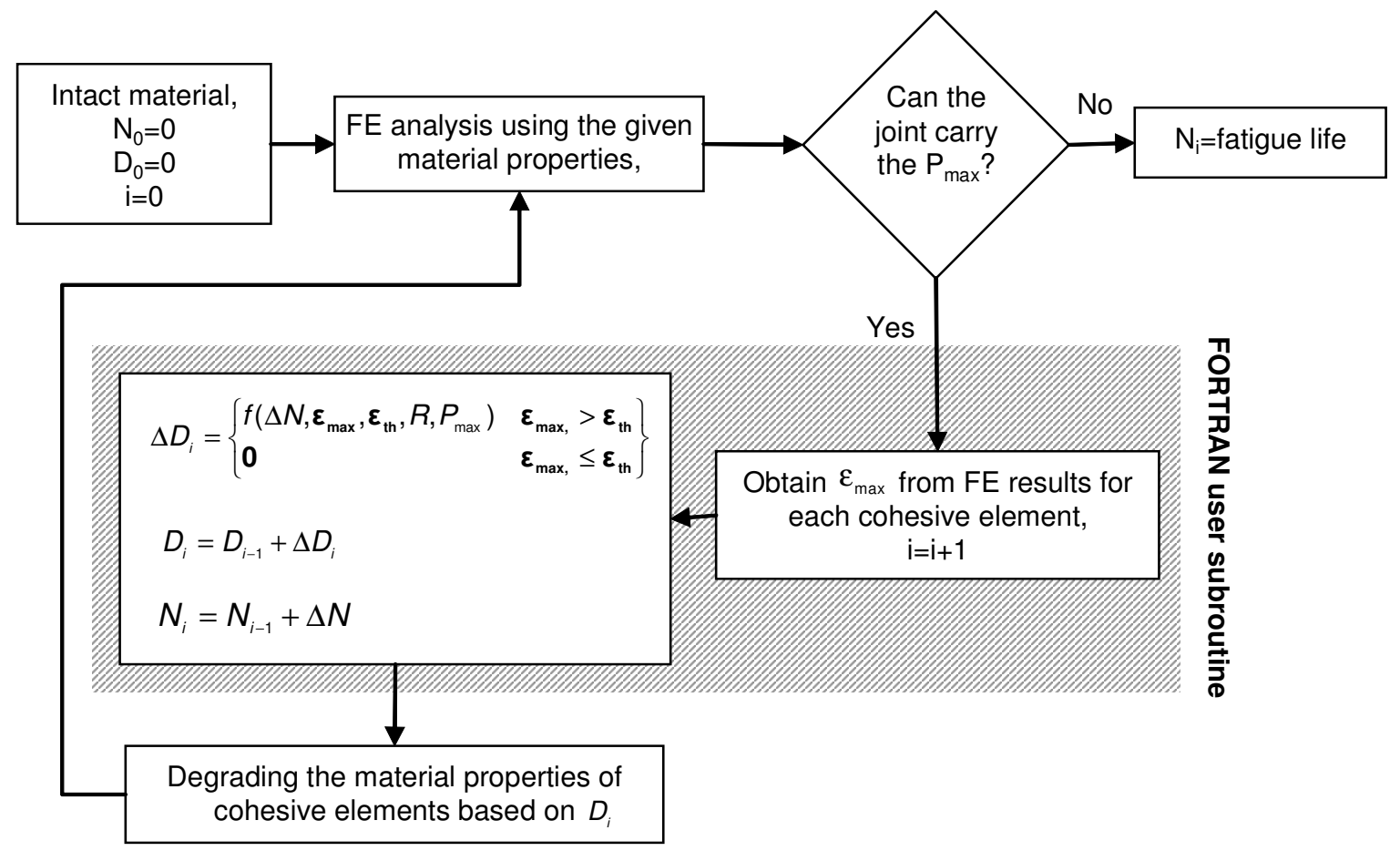

Fig. 11. The flowchart of the fatigue damage model in Abaqus/Standard 


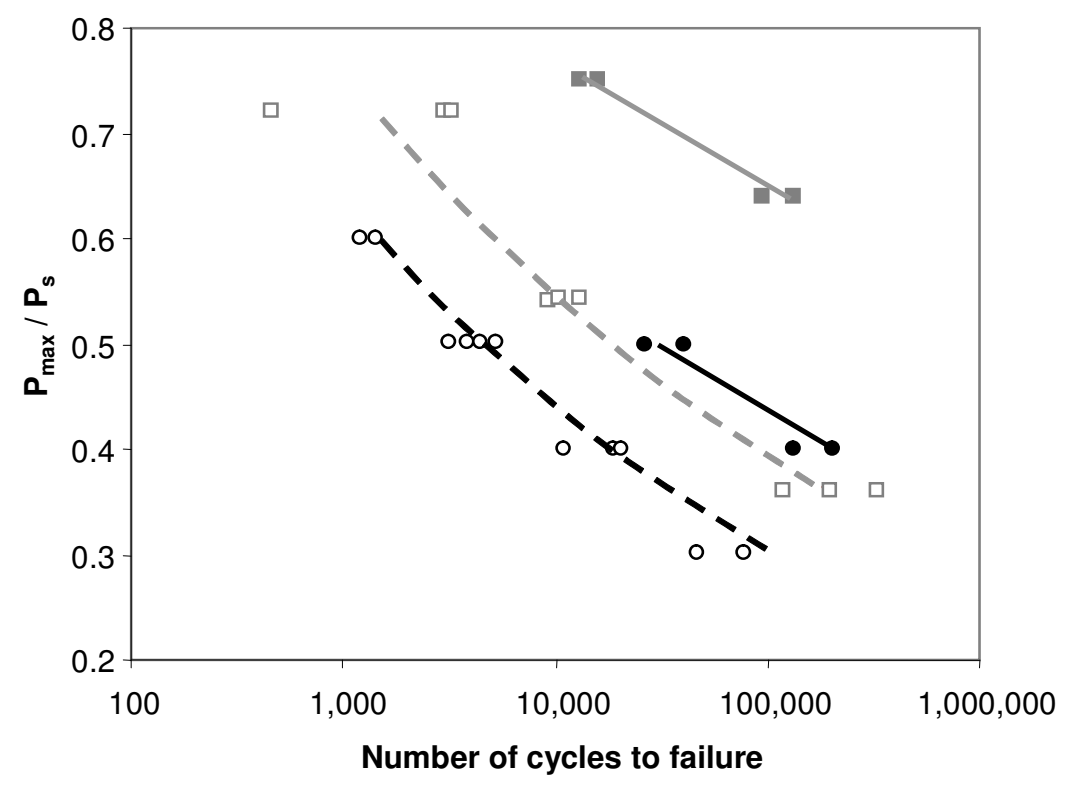

\begin{tabular}{|c|c|}
\hline Exp_FM 73M OST, R=0.1 & ○ Exp_AV119, $R=0.1$ \\
\hline 0.1 & - - Num_AV119, R=0.1 \\
\hline Exp_FM 73M OST, R=0.5 & 口 Exp_AV119, $R=0.5$ \\
\hline Im_FM 73M OST, R=0.5 & -- Num_AV119, R=0.5 \\
\hline
\end{tabular}

Fig. 12. Comparison between the experimental (data points) and numerical (curves) load-life results 


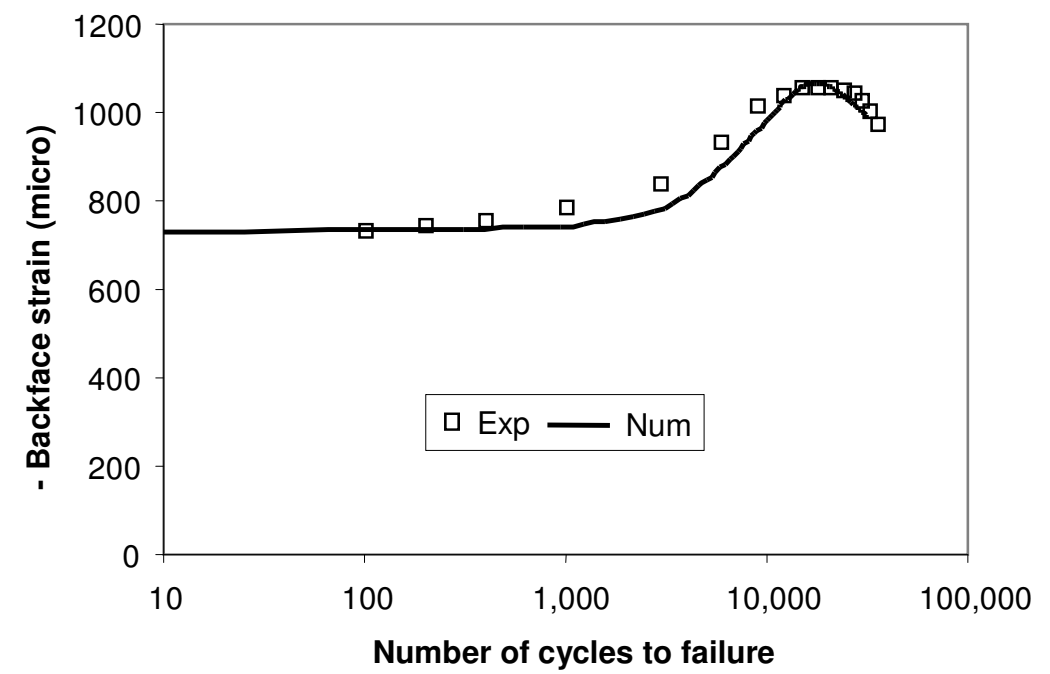

Fig. 13. Comparison of the typical predicted and measured backface strain variations at $\mathbf{1} \mathbf{~ m m}$ inside the overlap, $R=0.1$ and maximum fatigue load of $50 \%$ of static strength 